\title{
Studies on calcium absorption from milk using a double-label stable isotope technique
}

\author{
BY SUSAN J. FAIRWEATHER-TAIT ${ }^{1}$, AMANDA JOHNSON ${ }^{1}$, J. EAGLES ${ }^{1}$, \\ SMITA GANATRA ${ }^{2}$, H. KENNEDY ${ }^{3}$ AND M. I. GUR R ${ }^{2}$ \\ ${ }^{1}$ AFRC Institute of Food Research, Norwich Laboratory, Colney Lane, Norwich NR4 $7 U A$ \\ ${ }^{2}$ Milk Marketing Board, Thames Ditton, Surrey KT7 OEL \\ ${ }^{3}$ West Norwich Hospital, Bowthorpe Road, Norwich NR1 3SR
}

(Received 5 Jamuary 1989 - Accepted 18 April 1989)

\begin{abstract}
Calcium absorption was measured in ten male volunteers from skimmed milk, Ca-enriched skimmed milk or watercress (Nasturtium officinale) soup. The foods were labelled extrinsically with $30 \mathrm{mg}{ }^{44} \mathrm{Ca}$. Shortly after consuming the labelled meal, each subject was given an intravenous injection of $3 \mathrm{mg}{ }^{42} \mathrm{Ca}$. Fractional absorption from the oral dose was determined from plasma and urine samples collected 24 $72 \mathrm{~h}$ later, using fast atom bombardment mass spectrometry to measure isotope ratios. The values for urine and plasma were in good agreement. Mean percentage absorption was 45.5 (SEM 1.9) \% from the skimmed milk, 35.7 (SEM 4.7) \% from the Ca-enriched milk and 27.4 (SEM 1.9) \% from the watercress soup. The effect of consuming $568 \mathrm{ml}(1 \mathrm{pint})$ Ca-enriched milk each day for 4 weeks on the efficiency of absorption of $\mathrm{Ca}$ was studied. Although there was no statistically significant difference between $\mathrm{Ca}$ absorption before and after the supplementation period, the results were considered to be somewhat inconclusive due to the small number of subjects and wide individual variation in $\mathrm{Ca}$ absorption.
\end{abstract}

Calcium absorption: Milk calcium: Double-label stable isotope technique

Calcium in milk is generally considered to have a higher bioavailability than that from cereals and vegetables, but there is little evidence to substantiate this. The present study was designed to compare $\mathrm{Ca}$ absorption from skimmed milk and a Ca-enriched skimmed milk (Vital ${ }^{\circledR}$; Express Foods Group) with watercress (Nasturtium officinale) soup, using the stable isotope ${ }^{44} \mathrm{Ca}$ to label the endogenous $\mathrm{Ca}$ in the food, and at the same time administering ${ }^{42} \mathrm{Ca}$ intravenously in order to measure true $\mathrm{Ca}$ absorption from the oral dose (DeGrazia et al. 1965).

Although the amount of $\mathrm{Ca}$ available for absorption undoubtedly differs between individual foods and diets, the situation is further complicated by the fact that intestinal adaptation may take place in response to the level of $\mathrm{Ca}$ intake in terms of a changed efficiency of absorption (Malm, 1953; Birge et al. 1969). The absorption study on milk was repeated after each subject had consumed $568 \mathrm{ml}$ (1 pint) Vital (skimmed milk enriched with calcium gluconate, providing approximately $1000 \mathrm{mg} \mathrm{Ca}$ extra/d; Express Foods Group, South Ruislip, Middx) each day over a 4-week period, the objective being to determine whether or not the increased $\mathrm{Ca}$ intake had an effect on the efficiency of $\mathrm{Ca}$ absorption.

\section{MATERIALS AND METHODS}

Ten adult male volunteers (mean age 35.1 (SEM 2.9) years, clothed weight 70.0 (SEM 2.0) kg; height 1.773 (SEM 0.021) m) were recruited from the staff at the Institute of Food Research, Norwich Laboratory, and their habitual $\mathrm{Ca}$ intake estimated by means of a locally developed questionnaire, similar to that used by Nelson et al. (1988). 
Table 1. Composition of watercress (Nasturtium officinale) soup $(0.524 \mathrm{~g}$ calcium $/ \mathrm{kg})$

\begin{tabular}{llcc}
\hline Ingredients & $\begin{array}{c}\text { Amount } \\
(\mathrm{g} / \text { portion })\end{array}$ & $\begin{array}{c}\text { Ca content } \\
(\% \text { of total Ca })\end{array}$ \\
\hline Watercress & 66 & 76 \\
Parsnips & 20 & 6 \\
Carrots & 20 & 8 \\
Onions & 20 & 5 \\
& Potatoes & 66 & 4 \\
& Vegetable stock & 58 & 1 \\
\hline
\end{tabular}

The subjects were divided into two equal groups with similar mean $\mathrm{Ca}$ intakes and, following an overnight fast, each subject was given $250 \mathrm{~g}$ watercress soup (containing $131 \mathrm{mg} \mathrm{Ca}$, Table 1), to which had been added $30 \mathrm{mg}{ }^{44} \mathrm{Ca}$. The subjects refrained from eating for a further $4 \mathrm{~h}$ during which time $(2-3 \mathrm{~h}$ after the meal, that is when the plasma ${ }^{44} \mathrm{Ca}$ was at its highest level) they were given a $3 \mathrm{mg}$ intravenous (i.v.) injection of ${ }^{42} \mathrm{Ca}$ into the anticubital vein. The following morning a $10 \mathrm{ml}$ blood sample and a saliva sample were taken for analysis. Urine collections $(24 \mathrm{~h})$ were carried out for $6 \mathrm{~d}$ commencing immediately after the isotopically labelled meal.

On a separate occasion the previously described procedure was repeated but instead of the labelled meal five of the subjects were given $136 \mathrm{ml}$ skimmed milk (containing $150 \mathrm{mg}$ $\mathrm{Ca}$ ), and the other five $83 \mathrm{ml}$ Vital, a commercial skimmed milk enriched with calcium gluconate (containing $154 \mathrm{mg} \mathrm{Ca}$ ); an additional $30 \mathrm{mg}{ }^{44} \mathrm{Ca}$ were added to each portion of milk. The soup and milk were given in random order to eliminate any effects of time, and the subjects did not all participate on the same day. Each subject was then given $568 \mathrm{ml}$ (1 pint) Vital (1050 $\mathrm{mg} \mathrm{Ca}$ ) to consume daily, in addition to their normal diet, for a period of 4 weeks. They were asked to continue their usual dietary regimen, as identified from the $\mathrm{Ca}$ questionnaire, and to avoid any high- $\mathrm{Ca}$ foods that were not a regular part of their diet. At the end of the 4 weeks, the $\mathrm{Ca}$ absorption study from milk was repeated.

\section{Validation of use of extrinsic label for $\mathrm{Ca}$}

Fresh intact watercress plants (Fobdown Farm, New Arlingford, Hants) were placed in deionized water and half were intrinsically labelled with ${ }^{47} \mathrm{Ca}\left(\mathrm{CaCl}_{2} ;\right.$ Amersham International ple, Amersham, Bucks) by adding the radioisotope to the water and harvesting the leaf and upper stem (which contained approximately $8 \%$ of the ${ }^{47} \mathrm{Ca}$ content of the plant) $3 \mathrm{~d}$ later. The watercress was homogenized with deionized water $(20 \mathrm{~g}$ fresh leaves plus upper stem with $60 \mathrm{ml}$ water) and $5 \mathrm{ml}$ homogenate were given by gastric intubation to sixteen rats.

Extrinsically labelled portions of the watercress were prepared in the same way by adding the isotope to unlabelled watercress homogenate just before intubation. The percentage retention of the ${ }^{47} \mathrm{Ca}$ was measured by whole body counting using a small animal gamma counter (NE8112, NE Technology Ltd, Beenham, Berks) $7 \mathrm{~d}$ post-dosing, as described previously (Fairweather-Tait $\&$ Wright, 1985). There was no significant difference between the groups given extrinsically labelled watercress (Ca retention $80 \cdot 3$ (SEM 1.2) \%) and those given intrinsically labelled watercress (Ca retention $76 \cdot 3$ (SEM 2.2)\%).

\section{Preparation and administration of stable isotopes}

Two enriched isotopes were obtained from Oak Ridge National Laboratory (Tennessee, USA) as calcium carbonate: ${ }^{22} \mathrm{Ca}\left(94 \cdot 10\right.$ atom \%) and ${ }^{44} \mathrm{Ca}(98.78$ atom \%). 
The ${ }^{44} \mathrm{Ca}$ solution was prepared by dissolving the calcium carbonate in concentrated Aristar hydrochloric acid $\left(2.5 \mathrm{~g} \mathrm{CaCO}_{3}\right.$ plus $\left.5 \mathrm{ml} \mathrm{HCl}\right)$, adjusting the $\mathrm{pH}$ to 6.0 with $1 \mathrm{M}$ sodium hydroxide and making the solution up to a final volume of $100 \mathrm{ml}$. The ${ }^{44} \mathrm{Ca}$ solution for injection was prepared in a similar manner and 5-ml portions were dispensed into ampoules and sterilized. The ${ }^{42} \mathrm{Ca}$ concentration of the solution for injection was 0.701 $\mathrm{mg} / \mathrm{ml}$. The exact quantity of isotope given to each subject was measured, in the case of the ${ }^{44} \mathrm{Ca}$ by weighing the dispensed volume (approximately $3 \mathrm{ml} / \mathrm{dose}$ ) and in the case of the i.v. ${ }^{42} \mathrm{Ca}$ by weighing the loaded syringe before and after injection (approximately $5 \mathrm{ml} /$ dose).

\section{Atomic absorption spectroscopy $(A A S)$}

The Ca concentration of the test meals, enriched solutions of ${ }^{44} \mathrm{Ca}$ and ${ }^{42} \mathrm{Ca}$, plasma and saliva $24 \mathrm{~h}$ after the test meals, and $24 \mathrm{~h}$ urine collections 2 and $3 \mathrm{~d}$ post-dosing were measured.

(a) The milks were subjected to a wet-digestion procedure in which 5 -ml portions (in triplicate) were heated at $100^{\circ}$ for $20 \mathrm{~min}$ with $25 \mathrm{ml}$ concentrated Analar nitric acid, followed by dropwise addition of hydrogen peroxide. The solution was transferred to a volumetric flask and made up to volume with distilled water. Further dilutions were made to provide a final $\mathrm{Ca}$ concentration of between 1 and $6 \mu \mathrm{g} / \mathrm{ml}$.

(b) Subsamples of the watercress soup were dried and 5-g (in quadruplicate) portions were heated to $480^{\circ}$ for $48 \mathrm{~h}$, the ash taken up in hot concentrated Analar $\mathrm{HCl}$, and the solution made up to volume with distilled water, and diluted as described previously.

Lanthanum chloride was added to all solutions before making up to final volume to provide each sample undergoing AAS with an $\mathrm{LaCl}_{2}$ concentration of $10 \mathrm{~g} / 1$. Certified reference materials (National Bureau of Standards, Office of Standard Reference Materials, Washington, DC, USA) were also analysed for Ca to confirm analytical accuracy.

\section{Fast atom bombardment (FAB) mass spectrometry}

Blood was collected in heparinized tubes, centrifuged, the plasma removed and trichloroacetic acid $(35 \mathrm{~g} / 1 ; \mathrm{TCA})$ added at a ratio of 3 parts $: 1$ part plasma. The mixture was allowed to stand for $15 \mathrm{~min}$ at $4^{\circ}$, centrifuged and the deproteinized supernatant fraction removed.

The deproteinized plasma ( $1 \mathrm{ml}$ portions) was evaporated to dryness under an infra-red lamp and redissolved with $100 \mu \mathrm{l} 2 \mathrm{M}$-Aristar $\mathrm{HNO}_{3}$. The urine was deproteinized using TCA as described previously, and the saliva by adding a few drops of concentrated Aristar $\mathrm{HCl}$. The urine $\mathrm{Ca}$ was concentrated by precipitating the $\mathrm{Ca}$ as oxalate (Jiang \& Smith, 1987 ) by adding $2.5 \mathrm{ml}$ saturated ammonium oxalate solution to $2.5 \mathrm{ml}$ urine, mixing, centrifuging and discarding the supernatant fraction. The oxalate was redissolved in $100 \mu 11 \mathrm{M}-\mathrm{HCl}$.

Samples and standards were dispensed in $2 \mu 1$ portions onto the central area of the copper probe tip of the direct insertion probe and dried in a vacuum lock before being inserted into the FAB source of the MS80 RFA mass spectrometer (Kratos Analytical Instruments, Manchester) operating at a resolution of 3000 . The precise masses of various $\mathrm{Ca}$ isotopes from $2 \mu \mathrm{l}$ calcium nitrate ('SpectroSol'; $\mathrm{BDH}$, Poole, Dorset) were used to calibrate the electric sector scan of the mass range 40-44 daltons. The mass spectrometer was scanned five times and the next seventy-five consecutive scans of $3 \mathrm{~s}$ duration were recorded and averaged. Each scan consisted of four $0.15 \mathrm{~s}$ settling times between sweeping the 'lock mass' at $\mathrm{m} / \mathrm{z} 39.9626$ of the ${ }^{40} \mathrm{Ca}$ isotope in $0.3 \mathrm{~s}$ and then switching sequentially to $\mathrm{m} / \mathrm{z} 43.9555, \mathrm{~m} / \mathrm{z} 41.9586$ and $\mathrm{m} / \mathrm{z} 39.9626$ for $0.7 \mathrm{~s}$ each. Each sample was analysed three times and the results averaged. Enriched samples were 'bracketed' with runs of 
unenriched samples. The ${ }^{44} \mathrm{Ca}:{ }^{40} \mathrm{Ca}$ and ${ }^{42} \mathrm{Ca}:{ }^{40} \mathrm{Ca}$ ratios were determined by calculating the area under the peaks by computer.

\section{Calculation of Ca absorption and statistical treatment}

Assuming that both the orally and i.v. administered isotopes were metabolized at the same rate once equilibrium was reached, absorption from the oral dose was calculated in plasma, saliva and urine according to the following equation (Yergey et al. 1987):

$$
\text { percentage absorption }=\frac{\left(\text { na }{ }^{44} \mathrm{Ca}\right)\left({ }^{42} \mathrm{Ca} \text { i.v. }\right) \times \Delta \% \mathrm{XS}{ }^{44} \mathrm{Ca} \times 100}{\left(\mathrm{na}^{42} \mathrm{Ca}\right)\left({ }^{44} \mathrm{Ca} \text { oral }\right) \times \Delta \% \mathrm{XS}{ }^{42} \mathrm{Ca}},
$$

where na is the ratio of the two $\mathrm{Ca}$ isotopes in nature, i.v. and oral refer to the exact dose given, and $\Delta \% \mathrm{XS}$ represents the degree to which a particular ratio differs from natural levels.

Paired $t$ tests were used to compare percentage $\mathrm{Ca}$ absorption (measured in $24 \mathrm{~h}$ plasma) from the skimmed milk, Vital and watercress soup. The initial and final absorption values from both milks were also compared by paired $t$ tests. The relation between percentage absorption calculated from $24 \mathrm{~h}$ plasma and from days 2 and 3 urine, and $24 \mathrm{~h}$ saliva were examined by regression analysis.

\section{Ethical consideration}

The study was approved by the Institute of Food Research Ethical Committee.

\section{RESULTS}

The Ca intake of the subjects, as estimated from the questionnaire, is shown in Table 2. There was quite a wide range in intake, from 500 to $1800 \mathrm{mg} / \mathrm{d}$, with approximately $60 \%$ of the total $\mathrm{Ca}$ being provided by dairy products.

The percentage absorption of $\mathrm{Ca}$ from the two milks and watercress soup when measured in plasma $24 \mathrm{~h}$ post-dosing is shown in Fig. 1. The mean absorption for all ten subjects from the soup was 27.4 (SEM 1.9) \%, for the five subjects given skimmed milk 45.5 (SEM 1.9 ) $\%$ and for the five given Vital 35.7 (SEM 4.7) \%. When absorptions from milk and watercress soup were compared in each group of five subjects, it was shown that the Ca was less well absorbed from watercress soup than from skimmed milk $(P<0.001)$, but there was no statistically significant difference between watercress soup and Vital, probably due to the wide range of absorption values seen in the Vital group, nor was there any difference between percentage $\mathrm{Ca}$ absorption from skimmed milk and Vital.

The relation between saliva and plasma, collected $24 \mathrm{~h}$ post-dosing, is shown in Fig. 2 . The two sets of absorption values were related $(R 0.69, P<0.01)$, but there was some discrepancy between the theoretical $(1: 1$ ratio) and the fitted lines. Fig. 3 shows that there was a better agreement between $\mathrm{Ca}$ absorption estimated from $24 \mathrm{~h}$ plasma and urine

Table 2. Calcium intake $(\mathrm{mg} / \mathrm{d})$ of ten male subjects, estimated by questionnaire (Mean values with their standard errors and range)

\begin{tabular}{lrrrr}
\hline & Mean & SEM & Range \\
& & 723 & 114 & $168-1366$ \\
& Dairy sources & 484 & 111 & $148-1046$ \\
Non-dairy sources & 1207 & 137 & $498-1835$ \\
Total Ca & & & \\
\hline
\end{tabular}




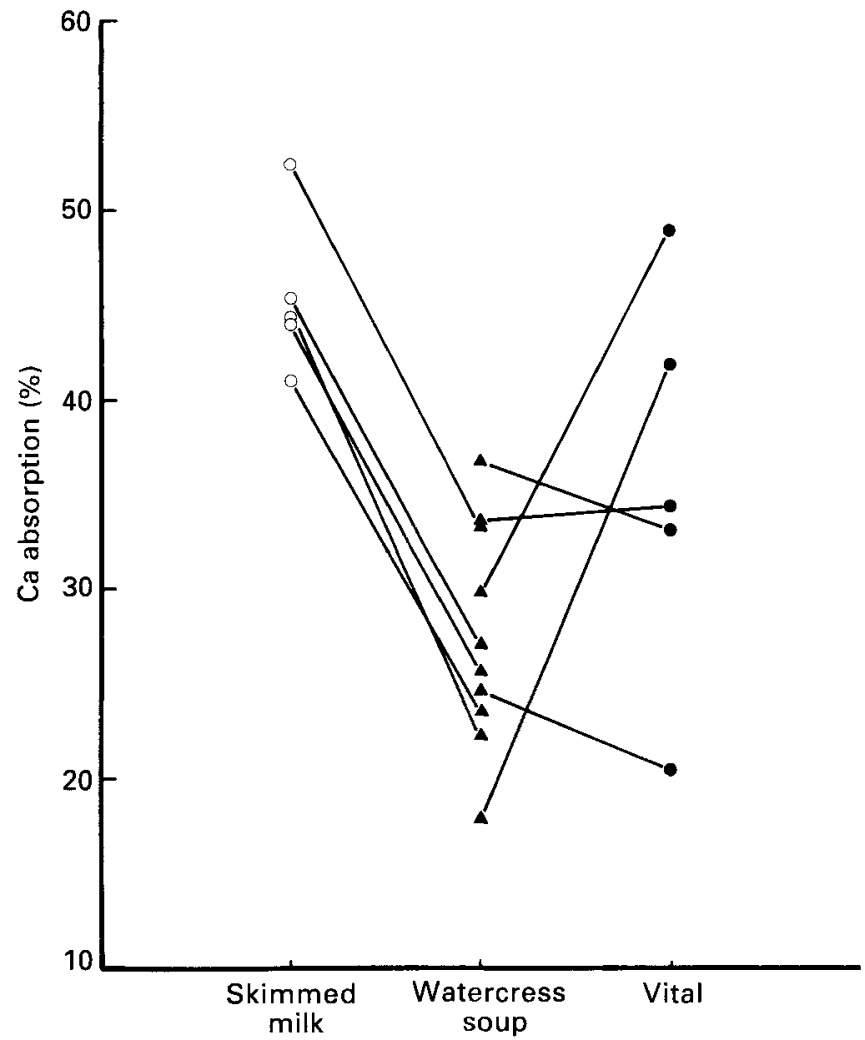

Fig. 1. Calcium absorption (\%) from skimmed milk (O), Ca-fortified milk (Vital; Express Foods Group) (O), and watercress (Nasturtium officinale) soup $(\boldsymbol{\Delta})$ in ten adult men as measured from blood plasma collected $24 \mathrm{~h}$ post-dosing using a double-label stable isotope technique (for details, see. p. 380).

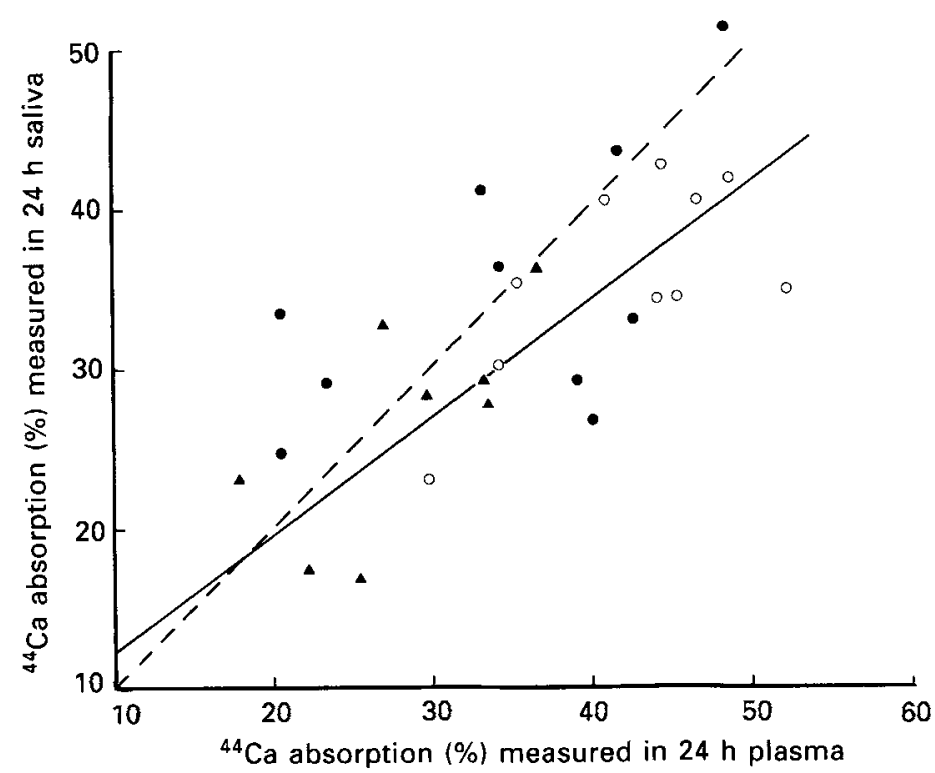

Fig. 2 Calcium absorption (\%) measured from saliva and plasma collected $24 \mathrm{~h}$ post-dosing, from skimmed milk (O), Ca-fortified milk (Vital; Express Foods Group) (O), and watercress (Nasturtium officinale) soup (A). For details of procedures, see p. 380. (---), Perfect $(1: 1)$ agreement; $(-)$, fitted to the values using regression analysis. 


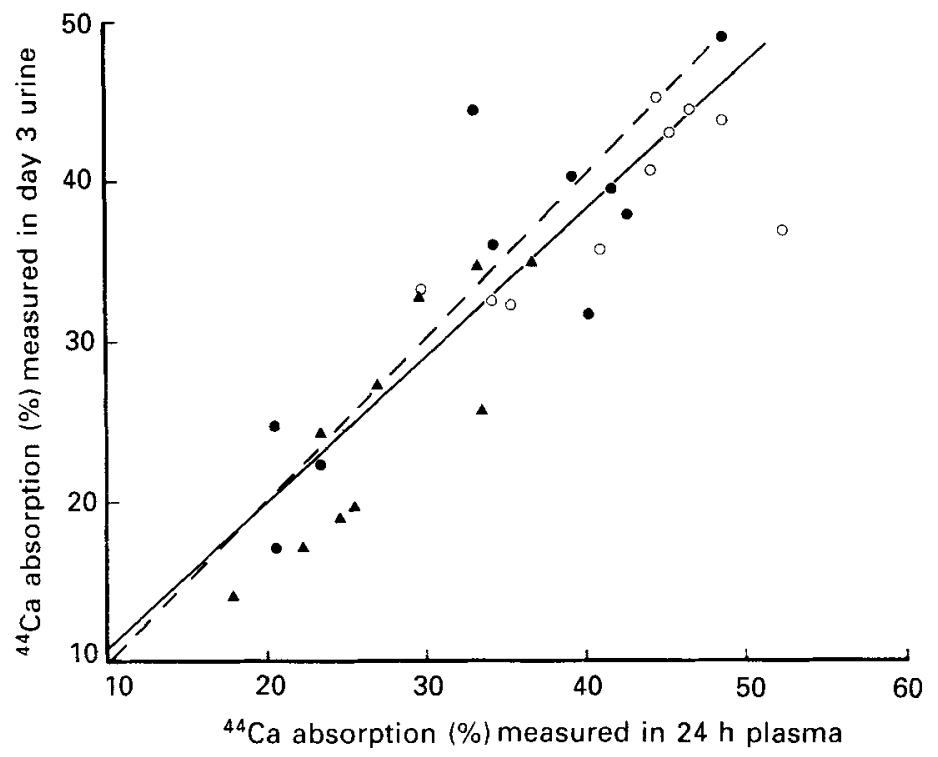

Fig. 3. Calcium absorption (\%) measured from urine collected $3 \mathrm{~d}$ and plasma $24 \mathrm{~h}$ post-dosing, from skimmed milk (O), Ca-fortified milk (Vital; Express Foods Group) (O), and watercress (Nasturtium officinale) soup ( $\mathbf{A}$ ). For details of procedures, see p. 380. (--) Perfect (1:1) agreement; (- - ), fitted to the values using regression analysis.

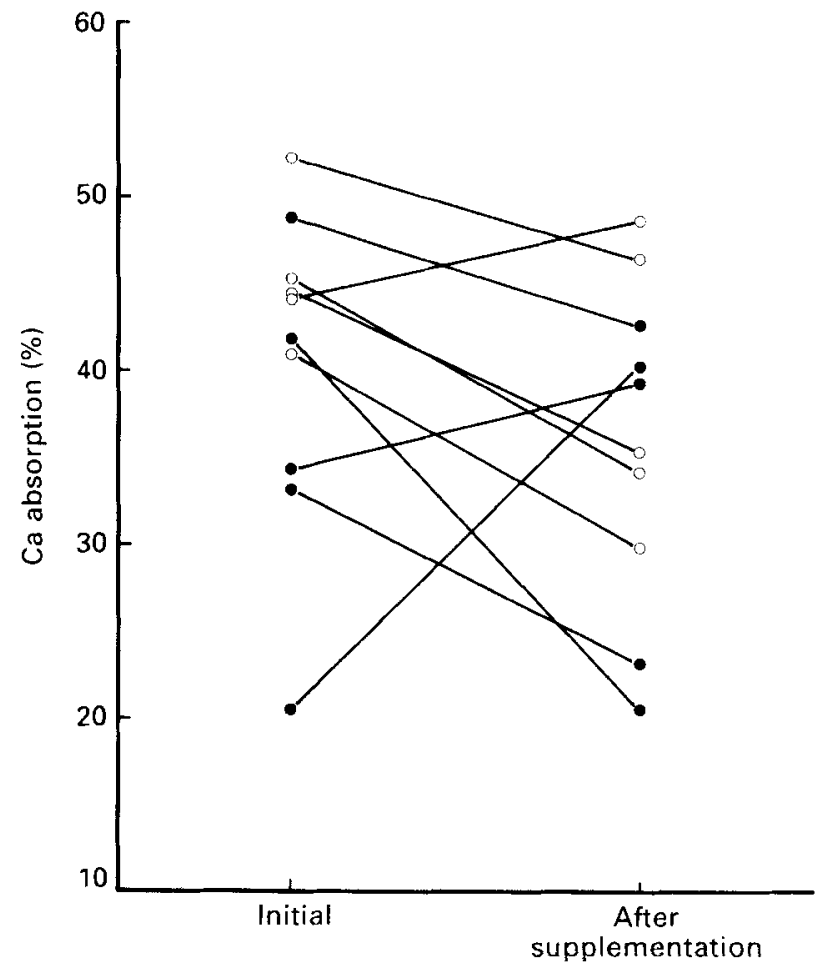

Fig. 4. Effect of milk supplementation on percentage calcium absorption in men from skimmed milk $(\mathrm{O})$ and $\mathrm{Ca}-$ fortified milk (Vital; Express Foods Group) (O) before and after supplementation with $568 \mathrm{ml}$ (1 pint) Vital daily for 4 weeks. For details of procedures, see p. 380. 
collected $3 \mathrm{~d}$ post-dosing $(R 0.88, P<0.001)$. Similar results were found with day 2 urine $(R 0.86, P<0.001)$, but these values are not shown.

There appeared to be no significant effect of consuming 1 pint Vital daily for 4 weeks on the efficiency of $\mathrm{Ca}$ absorption. The results for the subjects are shown in Fig. 4. Mean initial absorption for the ten men was 40.6 (SEM $2 \cdot 9$ ) \% and final absorption $36 \cdot 1$ (SEM 3.0 ) \%. The mean response was similar for both types of milk used for the test meal.

\section{DISCUSSION}

A reliable estimate of $\mathrm{Ca}$ absorption may be obtained using combined oral and i.v. tracers, as first developed by DeGrazia et al. (1965) using ${ }^{45} \mathrm{Ca}$ and ${ }^{47} \mathrm{Ca}$. Using radioisotopes, fractional intestinal $\mathrm{Ca}$ absorption can be determined from the ratio of the specific activities of oral ${ }^{47} \mathrm{Ca}$ :i.v. administered $\mathrm{Ca}$ in a plasma or urine sample taken $24 \mathrm{~h}$ after simultaneous administration of the two isotopes. This technique circumvents the necessity for complete metabolic balances and is, therefore, simpler, more attractive, and not prone to the errors inevitably associated with faecal collections. Unlike the single-label techniques (which measure apparent absorption because re-excreted tracer cannot be distinguished from unabsorbed tracer) the results obtained from the double-label technique are a measure of true $\mathrm{Ca}$ absorption. The method has been shown to yield results that are comparable with methods such as whole body counting (Roth \& Werner, 1985).

More recently, because of increasing awareness of the hazards of ionizing radiation, efforts have been made to use stable isotopes instead of radioisotopes wherever possible. Thus, Yergey et al. (1987) used an oral dose of ${ }^{44} \mathrm{Ca}(0.2-0.5 \mathrm{mg} / \mathrm{kg}$ body-weight) coupled with an intravenous dose of ${ }^{42} \mathrm{Ca}(0.02-0.1 \mathrm{mg} / \mathrm{kg}$ body-weight) to measure fractional $\mathrm{Ca}$ absorption in two premature infants and one adult from a commercial milk formula. They employed thermal-ionization mass spectrometry to quantify the isotopic enrichment in sequential urine samples, and found that the time required to obtain constant absorption results was longer (about $24 \mathrm{~h}$ ) in the adult than in the infants (about $10 \mathrm{~h}$ ). This they thought might be explained by differences in intestinal transit time. They have recently published further information from this study, using ${ }^{46} \mathrm{Ca}$ instead of ${ }^{42} \mathrm{Ca}$, and discuss both the thermal ionization mass spectrometry methodology and the double-label technique (Hillman et al. 1988). Lehmann \& Kessler (1982) used a similar procedure (one healthy volunteer given $184 \mathrm{mg}{ }^{44} \mathrm{Ca}$ oral dose, and $27 \mathrm{mg}{ }^{42} \mathrm{Ca}$ i.v.) in a preliminary study with field desorption mass spectrometry, and found reasonably good agreement between percentage Ca absorption calculated from plasma, urine and saliva samples taken more than $24 \mathrm{~h}$ after the oral dose. The results of the present study also showed agreement between plasma, urine and saliva, and if one accepts that plasma is the most appropriate body fluid in which to measure isotopic enrichment, the next best was urine collected $2-3 \mathrm{~d}$ post-dosing. The latter has the advantage of being less invasive and more suitable for studies where blood sampling is best avoided, as in infants, or where it is impracticable or difficult to organize.

The amounts and timing of isotope administration are an important consideration of the experimental design because, unlike radioisotopes, stable isotopes are not strictly tracers. Because they are naturally present in all tissues and foods, the dose administered must be large enough to cause measurable enrichment in the samples to be analysed. Regarding the oral dose, until more experimental information is available, it must be assumed that the added isotope behaves in a similar fashion to the $\mathrm{Ca}$ contained in the test food or $\mathrm{Ca}$ containing substance. The rat study described in the present paper demonstrated the validity of using an extrinsic label to measure endogenous $\mathrm{Ca}$ in watercress. It was not possible to validate the use of an extrinsic label for milk. The preparation of intrinsically labelled cows' milk is extremely expensive and for this reason, coupled with time 
constraints, it was not possible to carry out a study along the lines of that described for watercress. However, the validity of using an extrinsic label to measure Ca absorption from milk is currently under investigation by Weaver et al. (1988) who have previously shown that extrinsic labels can be used for low-oxalate (e.g. milk) but not high-oxalate food (Weaver et al. 1987). Preliminary data indicate that extrinsic labelling techniques are valid (Martin et al. 1989). In a similar study, in which spinach and milk were compared, Heaney et al. (1988) labelled the spinach intrinsically and the milk extrinsically, but did not discuss the labelling aspect of the methodology. Other studies in the literature report the use of radio-Ca as an extrinsic label for milk (Kocián et al. 1973; Recker et al. 1988). Regarding the intravenous dose, several studies have used amounts of isotope in the region of $30 \mathrm{mg}$, which has been calculated to be equivalent to $2 \%$ of the rapidly miscible component of the Ca pool (Heaney \& Skillman, 1971). Thus the dose used in the present study (approximately $3 \mathrm{mg}{ }^{42} \mathrm{Ca}$ ), an order of magnitude less than many other studies, is unlikely to perturb steady state conditions. The appropriate time of administration of the i.v. dose cannot be identified with any certainty. Ideally the i.v. administered isotope should be present in the blood at the same time as the orally administered isotope but this is not possible because the latter is absorbed from the intestine over an extended time period. Since orally administered $\mathrm{Ca}$ isotope appears to reach a maximum in the blood $2-3 \mathrm{~h}$ after ingestion (Kocián et al. 1973) we chose, like Lehmann \& Kessler (1982), to give the i.v. dose 2-3 h after the test meal in the hope that most of the two isotopes would be metabolized together.

The use of FAB mass spectrometry to measure inorganic isotopes is a very recent development. Smith (1983) was the first to use this method for $\mathrm{Ca}$ isotopes, and in a methodology paper has subsequently reported its use for measuring fractional true absorption of $\mathrm{Ca}$ by the double isotope technique (Smith et al. 1985). In the absence of a dedicated inorganic mass spectrometer, FAB offers an alternative method of measuring inorganic stable isotopes, but is less sensitive and generally less accurate than thermal ionization. It does, however, have the advantage of requiring less rigorous sample preparation (Pratt et al. 1987).

Differences in bioavailability of $\mathrm{Ca}$ from a variety of foods were reported more than 60 years ago in metabolic balance studies on children (Sherman \& Hawley, 1922), when milk was shown to be superior to vegetables with respect to $\mathrm{Ca}$ retention. There is very little information in the literature to support the widely held belief that the $\mathrm{Ca}$ in milk is particularly well absorbed by adults. Using ${ }^{47} \mathrm{Ca}$ as an extrinsic label in milk, Kocián et al. (1973) found apparent absorption (measured by whole body counting $7 \mathrm{~d}$ post-dosing) to be about $40 \%$ in five healthy males, which agrees quite well with our value of $45 \%$ for skimmed milk. Recker et al. (1988), using ${ }^{45} \mathrm{Ca}$ as an extrinsic label, found that $\mathrm{Ca}$ absorption in post-menopausal women from milk products (whole milk, chocolate milk, yoghurt, imitation milk, cheese) was similar to calcium carbonate, with means ranging from 22 to $27 \%$ from a $25 \mathrm{mg}$ dose. The present experiment re-affirms the results of the original balance studies on dairy and plant foods in that the $\mathrm{Ca}$ in skimmed milk was better absorbed than that in watercress soup. The reason for this is unclear but may be attributable to substances present in the watercress soup that bind $\mathrm{Ca}$ thereby rendering it less absorbable, e.g. oxalate (Pingle \& Ramasastri, 1978) and fibre (Kelsay et al. 1979), plus the fact that certain components of milk have been implicated as enhancers of $\mathrm{Ca}$ absorption, e.g. lactose (Charley \& Saltman, 1963) and casein (Lee et al. 1979).

With regard to the milk enriched with calcium gluconate, it has been shown that different $\mathrm{Ca}$ salts are absorbed with differing degrees of efficiency. For example, Nicar \& Pak (1985) found that calcium citrate had a higher bioavailability than calcium carbonate when given at doses of $1000 \mathrm{mg}$, and Spencer et al. (1966) showed that lactate was superior to gluconate. Using an oral Ca challenge of Ca salts in milk, Goddard et al. (1986) found that 
the peak effects of calcium gluconate were reached before carbonate and lactate, indicating a difference in metabolic response. The present experiment did not show a significant difference between calcium gluconate-enriched milk and skimmed milk. There was a wide variation in percentage $\mathrm{Ca}$ absorption between the individuals which, coupled with the small numbers in the groups, makes it impossible to reach a firm conclusion regarding the bioavailability of calcium in Vital. In particular one subject absorbed a particularly small fraction of Ca from Vital (approximately $20 \%$ ) on the first occasion, but absorbed double this amount on the second occasion.

Finally, the medium-term effects of consuming a higher $\mathrm{Ca}$ diet on absorption efficiency were addressed. Adaptation to differing $\mathrm{Ca}$ intakes has been shown to occur in man, whereby fractional $\mathrm{Ca}$ absorption is increased by a low-Ca diet and reduced by a high-Ca diet (Malm, 1958; Heaney et al. 1975), including milk supplementation, over 2 years (Recker \& Heaney, 1985). The adaptation is thought to occur primarily at the site of the ileum (Norman et al. 1981). The male subjects in the present study all appeared to have adequate intakes of $\mathrm{Ca}$, and when given $568 \mathrm{ml}$ ( 1 pint) Vital daily, their intakes approximately doubled. Over the 4-week period, this extra $\mathrm{Ca}$ appeared to have little or no effect on the efficiency of absorption of $\mathrm{Ca}$. Seven subjects had a reduced absorption, but in three subjects fractional absorption rose. It is possible that the time period was too short for any adaptive response to have manifested itself, and it is not possible to predict what the effects would be over a longer time period.

The authors are grateful to Express Foods Group, South Ruislip, Middlesex, for donating the Ca-enriched milk (Vital). They would also like to thank Miss B. Wharf for help with the blood sampling, $\mathrm{Mr} \mathrm{T}$. Fox for developing the $\mathrm{Ca}$ questionnaire, and $\mathrm{Mr} \mathrm{A}$. J. A. Wright for help with the animal study.

\section{REFERENCES}

Birge, S. J., Peck, W. A., Berman, M. \& Whedon, G. D. (1969). Study of calcium absorption in man: a kinetic analysis and physiologic model. Journal of Clinical Investigations 48, 1705-1713.

Charley, P. \& Saltman, P. (1963). Chelation of calcium by lactose: its role in transport mechanisms. Science 139, $1205-1206$

DeGrazia, J. A., Ivanovich, P., Fellows, H. \& Rich, C. (1965). A double isotope technique for measurement of intestinal absorption of calcium in man. Journal of Laboratory and Clinical Medicine 66, 822-829.

Fairweather-Tait, S. J. \& Wright, A. J. A. (1985). The effect of 'fibre-filler' (F-plan diet) on iron, zinc and calcium absorption in rats. British Journal of Nutrition 54, 585-592.

Goddard, M., Young, G. \& Marcus, R. (1986). Short-term effects of calcium carbonate, lactate and gluconate on the calcium-parathyroid axis in normal elderly men and women. American Journal of Clinical Nutrition 44, 653-658.

Heaney, R. P., Saville, P. D. \& Recker, R. R. (1975). Calcium absorption as a function of calcium intake. Journal of Laboratory and Clinical Medicine $\mathbf{8 5}, 881-890$.

Heaney, R. P. \& Skillman, T. G. (1971). Calcium metabolism in normal human pregnancy. Journal of Clinical Endocrinology 33, 661-669.

Heaney, R. P., Weaver, C. M. \& Recker, R. R. (1988). Calcium absorbability from spinach. American Journal of Clinical Nutrition 47, 707-709.

Hillman, L. S., Tack, E., Covell, D. G., Vieira, N. E. \& Yergey, A. L. (1988). Measurement of true calcium absorption in premature infants using intravenous ${ }^{46} \mathrm{Ca}$ and oral ${ }^{44} \mathrm{Ca}$. Pediatric Research $23,589-594$.

Jiang, X. \& Smith, D. L. (1987). Quantitation of stable isotopic tracer of calcium by fast atom bombardment mass spectrometry. Analytical Chemistry 59, 2570-2574.

Kelsay, J. L., Behall, K. M. \& Prather, E. S. (1979). Effect of fiber from fruits and vegetables on metabolic responses of human subjects. II. Calcium, magnesium, iron, and silicon balances. American Journal of Clinical Nutrition 32, 1876-1880.

Kocián, J., Skála, I. \& Bakos, K. (1973). Calcium absorption from milk and lactose-free milk in healthy subjects and patients with lactose intolerance. Digestion 9, 317-324.

Lee, Y.S., Noguchi, T. \& Naito, H. (1979). An enhanced intestinal absorption of calcium in the rat directly attributed to dietary casein. Agricultural and Biological Chemistry 47, 2009-2011. 
Lehmann, W. D. \& Kessler, M. (1982). Calcium absorption studies in man by stable isotope dilution and field desorption mass spectrometry. In Stable Isotopes, pp. 649-654 [H.-L. Smidt, H. Forstel and K. Heinzinger, editors]. Amsterdam: Elsevier Scientific Publishing Co.

Malm, O.J. (1953). On phosphate and phosphoric acid as dietary factors in the calcium balance of man. Scandinavian Journal of Clinical and Laboratory Investigation 5, 75-84.

Malm, O. J. (1958). Calcium requirement and adaptation in adult man. Scandinavian Journal of Clinical and Laboratory Investigation 10, Suppl. 36, 108-199.

Martin, B. R., Weaver, C. M. \& Smith, D. L. (1989). Calcium absorption from milk vs. calcium carbonate in college age women using stable isotopes. FASEB Journal 3, A771.

Nelson, M., Hague, G. F., Cooper, C. \& Bunker, V. W. (1988). Calcium intake in the elderly: validation of a dietary questionnaire. Journal of Human Nutrition and Dietetics 1, 115-127.

Nicar, M. J. \& Pak, Y. C. (1985). Calcium bioavailability from calcium carbonate and calcium citrate. Journal of Clinical Endocrinology and Metabolism 61, 391-393.

Norman, D. A., Fordtran, J. S., Brinkley, L. J., Zerwekh, J. E., Nicar, M. J., Strowig, S. M. \& Pak, C. Y. C. (1981). Jejunal and ileal adaptation to alterations in dietary calcium. Journal of Clinical Investigation 67, $1599-1603$

Pingle, U. \& Ramasastri, B. V. (1978). Effect of water-soluble oxalates in Amaranthus spp. leaves on the absorption of milk calcium. British Journal of Nutrition 40, 591-595.

Pratt, D. E., Eagles, J. \& Fairweather-Tait, S. J. (1987). Fast atom bombardment mass spectrometry method for monitoring zinc and calcium stable isotopes in bioavailability studies. Journal of Micronutrient Analysis 3 , $107-117$.

Recker, R. R., Bammi, A., Barger-Lux, M. J. \& Heaney, R. P. (1988), Calcium absorbability from milk products, an imitation milk, and calcium carbonate. American Journal of Clinical Nutrition 47, 93-95.

Recker, R. R. \& Heaney, R. P. (1985). The effect of milk supplementation on calcium metabolism, bone metabolism and calcium balance. American Journal of Clinical Nutrition 41, $254-263$.

Roth, P. \& Werner, E. (1985). Interrelation of radiocalcium absorption tests and their clinical relevance. Mineral Electrolyte Metabolism 11, 351-357.

Sherman, H. C. \& Hawley, E. (1922). Calcium and phosphorus metabolism in childhood. Journal of Biological Chemistry 53, 375-399.

Smith, D. L. (1983). Determination of stable isotopes of calcium in biological fluids by fast atom bombardment mass spectrometry. Analytical Chemistry 55, 2391-2393.

Smith, D. L., Atkin, C. \& Westenfelder, C. (1985). Stable isotopes of calcium as tracers: methodology. Clinica Chimica Acta 146, 97-101.

Spencer, H., Scheck, J., Lewin, I. \& Samachson, J. (1966). Comparative absorption of calcium from calcium gluconate and calcium lactate in man. Journal of Nutrition 89, 283-291.

Weaver, C. M., Martin, B. R., Ebner, J. S. \& Krueger, C. A. (1987). Oxalic acid decreases calcium absorption in rats. Journal of Nutrition 117, 1903 1906.

Weaver, C. M., Martin, B. R., Smith, D. L., Chambers, J. V. \& Noller, C. H. (1988). Endogenous labelling of bovine milk with the stable isotope ${ }^{44} \mathrm{Ca}$. Nutrition Research 8, 1183-1189.

Yergey, A. L., Vieira, N. E. \& Covell, D. G. (1987). Direct measurement of dietary functional absorption using calcium isotopic tracers. Biomedical and Environmental Mass Spectrometry 14, 603-607. 